\title{
Understanding the Trophodynamics of Yellowfin Tuna, Thunnus albacares (Bonnaterre, 1788) from the Western Bay of Bengal
}

\author{
Mamidi Satish Kumar ${ }^{1, *}$, Shubhadeep Ghosh ${ }^{1}$
}

${ }^{1}$ Visakhapatnam RC of ICAR-Central Marine Fisheries Research Institute Pandurangapuram, Ocean View Layout, Visakhapatnam-530003, Andhra Pradesh, India.

\section{Article History}

Received 19 April 2020

Accepted 30 October 2020

First Online 06 November 2020

\section{Corresponding Author}

Tel.: +918912543793

E-mail:

mamidi.satishkumar@gmail.com

\section{Keywords}

Feeding Intensity

Feeding Strategy

Index of Relative Importance

Western Bay of Bengal

Thunnus albacares

\begin{abstract}
The trophodynamics of Thunnus albacares (Bonnaterre, 1788) from the western Bay of Bengal was studied during $2012-2015$. Feeding intensity revealed that $34.6 \%$ of the fishes had empty-trace stomachs, $52.77 \%$ of the fishes had quarter full-half full stomachs and $12.44 \%$ of the fishes had three fourth full-gorged stomachs. Feeding intensity increased with an increase in body size of the fishes with high prey to predator weight ratios and with a third of the fishes above $160 \mathrm{~cm}$ fork length possessing three fourth full-gorged stomachs. Cephalopods (47\%) dominated the prey constituents, followed by semi digested finfishes and shellfishes (28\%), finfishes (16\%) and crustaceans (9\%). Significant shifts in prey items were observed with an increase in fish size. Though squids were predominant in the diet, however, with the increase in size, feeding shift has clearly been observed towards finfishes. Feeding preferences did not vary between sexes. Annual and seasonal similarities were recorded in their food and feeding habits. Prey-specific abundance indicated a relative specialized feeding pattern with high occurence of species belonging to the orders Teuthidae and Perciformes. Levins Standardized Niche Breadth Index of 0.16 indicated limited niche width in the feeding strategy of Thunnus albacares.
\end{abstract}

\section{Introduction}

Tunas are found all over the world in tropical and subtropical seas and are pelagic in nature. Globally tuna production has increased continuously from less than 0.6 million tonnes in 1950 to almost 16 million tonnes in 2016 (Fishery Global Information System FIGIS, 2016). During the last five decades, tuna accounted for half of the total global marine capture fisheries (FAO, 2016). Thunnus albacares is one of the most important oceanic tuna species in the world and there exists a targeted fishing for this species in several countries.

The western Bay of Bengal is one of the most productive ecosystems and has been extensively fished for its rich fishery resources since the past several years. Of late, tuna fishing has emerged as an important fishery activity in this region. Along the western Bay of Bengal, tuna fishery is represented by nine species belonging to five genera, Auxis, Euthynnus, Sarda, Katsuwonus and Thunnus. Targeted fishing is being carried out and now it has reached the status of a major industry with several private fishery entrepreneurs, involving actively with local fisherfolk in harvesting and processing tunas. Thunnus albacares (yellowfin tuna) forms the major component of the catch among the several species of tunas contributing to the fishery. The non-mechanised sector operating hooks and line mainly harvests $T$. albacares in this region (Rohit, Rao \& Rammohan, 2008; Rohit \& Rammohan, 2009).

Food is an important factor influencing the growth, migration and abundance of the fish stocks in time and space and it is one of the essential requisites for 
continuance of their vital needs. The nature of food and feeding habits depends on its habitat in the ecosystem, and it also varies along with the age, time and area. Availability of preferred food contents in the ecosystem (predator-prey relationship) is the basis for its survival and successful recruitment. For successful management of fishery stocks, it is essential to have prior knowledge of food and feeding habits with age, time and area. $T$. albacares is an apex predator actively hunting for its prey. The ecological role of apex predators in marine food web is of paramount significance as it is critical in the assessment on the impact of fishing on ecosystems (Kitchell, et al., 1999; Cox, et al., 2002; Watters, et al., 2003).

Few studies have reported the food and feeding habits of $T$. albacares from the Bay of Bengal (Vijaykumaran, et al., 1992; Pillai, et al., 1993; John, 1995; Govindaraj et al., 2000; Somvanshi, 2002; Rohit, et al., 2010; Rohit and Rammohan, 2009; Abdussamad et al., 2012; Pradeep, et al., 2014), albeit, with only two studies (Rohit et al., 2010; Rohit and Rammohan, 2009) from the western Bay of Bengal. All the above studies focussed only on qualitative and quantitative occurence on prey items with no in-depth analysis on the trophodynamics. The present study forms the first report from the region on annual, seasonal, size-wise and sex-wise analysis on the trophodynamics of $T$. albacares. Being an apex predator, T. albacares forms an important component of the food web, hence, information generated in the present study would be vital in understanding the structural changes brought about in the ecosystem when they are removed by fishing, therefore, facilitating ecosystem-based fisheries management.

\section{Materials and Methods}

Samples of $T$. albacares were collected randomly during 2012-2015 from Viskhapatnam, Kakinada, Pudimadaka and Bheemunipatnam fish landing centres of Andhra Pradesh, India, along the western Bay of Bengal and their fork length $(\mathrm{cm})$ and weight $(\mathrm{g})$ and sex was recorded. Using information from log-sheets, it was understood that $T$. albacares were caught using gillnets (mesh size of $175-200 \mathrm{~mm}$ ) and hooks and lines (hook number 3 using artificial baits) in locations with depths ranging from $30 \mathrm{~m}$ to beyond $200 \mathrm{~m}$, and at distances ranging from 25 nautical miles to 169 nautical miles from the shore. The temperature ranges in which they were caught varied from $25^{\circ} \mathrm{C}$ to $29^{\circ} \mathrm{C}$. Additionally, stomachs for large sized fishes were also collected from the point of processing or marketing at fishing villages and near-by available processing units after taking relevant biological information on length and weight and sex. Altogether 1,412 samples in fork length ranging from $18 \mathrm{~cm}$ to $186 \mathrm{~cm}$ were analysed during the study period. The samples were analysed on the same day in which the fish was landed to negate the impact of digestion on stomach size and content. Feeding intensities in various months were studied by the degree of fullness of the stomach in relation to the size of the fish. Stomachs were cut open from the individual fish and the contents were processed and preserved for further identification and for obtaining the weight. Care was taken to eliminate artificial bait, if any, found along with the diet. Stomach state was assessed based on the distension and the degree of fullness and were classified as empty, trace, quarter full, half full, three fourth full, full and gorged. For the ease of presentation of results and for resolving ambiguities over closely related stomach states, the states were merged as empty trace, quarter full-half full and three fourth full-gorged. Prey weight in relation to predator weight (excluding stomachs with empty - trace amounts of prey) was estimated, additionally to assess feeding intensity. Feeding intensity, both stomach fullness and prey weight to predator weight was assessed size-wise (fork length), separately for fishes below $40 \mathrm{~cm}$ size, between 40 and $60 \mathrm{~cm}$ size, between $60 \mathrm{~cm}$ and $80 \mathrm{~cm}$ size, between $80 \mathrm{~cm}$ and $100 \mathrm{~cm}$ size, between $100 \mathrm{~cm}$ and $120 \mathrm{~cm}$ size, between $120 \mathrm{~cm}$ and $140 \mathrm{~cm}$ size, between $140 \mathrm{~cm}$ and $160 \mathrm{~cm}$ size and above $160 \mathrm{~cm}$ size. The IRI $\%$ (Index of relative of importance) (Pinkas, et al., 1971) was used to assess the diet contents. IRI \% was calculated by summing the numerical and volumetric percentage values and multiplying by the frequency of occurrence percentage value. IRI \% was evaluated annually, seasonally, sex-wise and size-wise. Significant differences in prey items between sexes were ascertained by ANOVA. Multivariate analyses on IRI \% was carried out using PRIMER v. 6 (Clarke \& Gorley, 2006). Variations in the dietary composition in the sexes were identified from the annual IRI \% and the seasonal IRI\%. Prior to statistical analysis of data, IRI \% was square root transformed and Bray - Curtis similarity matrices were constructed, and hierarchical cluster analysis was performed. SIMPROF permutation was done to test the cluster significance in males and females.

Feeding strategy, the ability to specialize or generalize prey items was estimated using the method of Amundsen, et al., (1996). Prey-specific abundance was estimated as the percentage of a prey taxon comprised of all prey items in only those predators in which the actual prey occurs. The dietary niche breadth was estimated using the Levins Standardized Niche Breadth Index (Levins, 1968), which was estimated from Levins Niche Breadth Index. The index ranges from 0 to 1 , with 0 signifying that the species consumes a single prey and 1 signifying that the species exploits available preys in equal proportions.

\section{Results}

\section{Feeding Intensity}

Of the 1,412 specimens analyzed, in $34.6 \%$ of the fishes, the stomachs were found to be empty - trace, in $52.77 \%$, the stomachs were found to be quarter full-half 
full and in $12.44 \%$, the stomachs were found to be three fourth full-gorged. The size-based analysis of diet (Figure 1) showed an increasing feeding intensity with increase in body size. Empty stomachs dominated in the lower size groups and decreased with an increase in fish size, with highest number of empty stomachs recorded in the smallest fishes and the lowest number of empty stomachs recorded in the largest fishes. Highest prevalence of quarter full-half full stomachs was observed in the middle to higher size groups $(120 \mathrm{~cm}$ $140 \mathrm{~cm}$ fork length). Feeding intensity was highest in the largest size fishes with a third of the fishes above $160 \mathrm{~cm}$ fork length possessing three fourth full-gorged stomachs. Similarly, the ratio of prey to predator weight also, increased with an increase in the size of the fish (Figure 2). The highest values were recorded in fishes above $140 \mathrm{~cm}$ fork length.

\section{Index of Relative Importance \%}

Around 5,315 prey items were observed in the analysed samples. Prey items mainly consisted of cephalopods (47\%), semi digested finfishes and shellfishes (28\%), finfishes (16\%) and crustaceans (9\%) (Figure 3). Cephalopods, the most preferred prey, were contributed chiefly by squids. Occurence of squids in the stomachs were very high during November - March (IRI $\%$ of $68.22 \%$ ) forming two-third of the diet constituents. Finfishes formed the second most abundant diet component and were reported throughout the year, with the highest occurence in the stomach in June (IRI \% of $42.08 \%$ ), followed by January - February (IRI \% of $30.35 \%)$. Carangids, mackerel and deep water balistids and driftfishes were the most preferred finfishes. Among crustaceans, crabs and squilla were the most preferred prey. Crabs dominated the diet contents in
October (IRI \% of $44.65 \%$ ) and squilla during July August (IRI \% of 19.01\%).

The size-based diet analysis showed a difference in feeding habit with increase in body size. $T$. albacares up to $40 \mathrm{~cm}$ fork length size were feeding mostly on squid, crab, squilla, paste shrimp and crustacean larvae. Significant prey fishes in this size class were ribbonfish, mackerel, juvenile tuna and whitebaits constituting less than $10 \%$ of the diet. Beyond $40 \mathrm{~cm}$ fork length sizes, $T$. albacares became more generalized feeders, feeding on a variety of food items. Despite the different habits, \%IRI values indicated that squid was the most preferred item across all size classes with their proportion increasing with an increase in the size of the fish (average IRI\% of $32.83)$. Crabs were consumed more or less equally by all sizes of the fish (average IRI\% of 6.71). Though squilla, paste shrimp and crustacean larvae were favoured by smaller fishes of less than $60 \mathrm{~cm}$ in fork length, they were rarely preyed upon by fishes over $80 \mathrm{~cm}$ in fork length. The contribution of shrimps as prey was meagre (average IRI\% of 2.49). Though squids were predominant in the diet, however, with the increase in size, feeding shift has clearly been observed towards finfishes. In fishes measuring $100 \mathrm{~cm}$ fork length and above, finfishes constituted around $20 \%$ of the prey items. Among finfishes, mackerel was the most preferred (average IRI\% of 6.15), followed by sardines (average IRI\% of 2.69), Indian scad (average IRI\% of 2.15) and juveniles of little tuna (average IRI\% of 2.0). The detailed size based major prey items are represented in Figure 4.

In the sex-based analysis of diet components (Figure 5), the IRI\% showed statistically insignificant differences $(P>0.05)$ in prey preferences between the two sexes. Squids formed $47.26 \%$ of the prey items in males and $41.24 \%$ in females. Crustaceans (crabs,

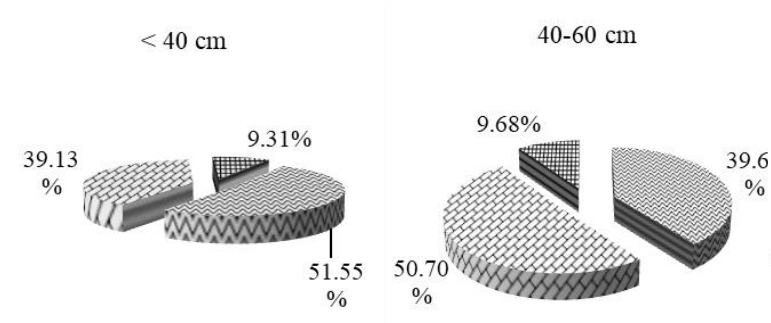

$100-120 \mathrm{~cm}$
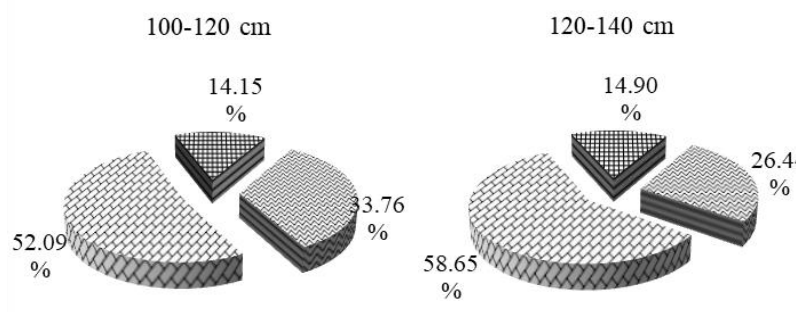

$60-80 \mathrm{~cm}$

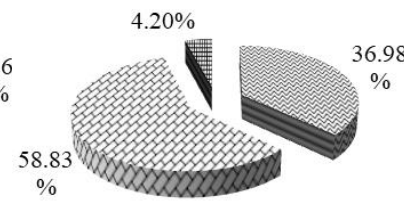

$140-160 \mathrm{~cm}$

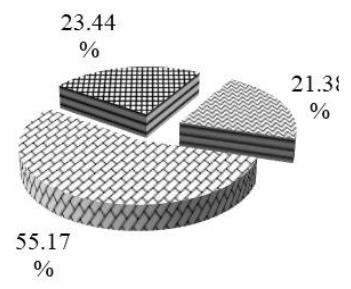

$80-100 \mathrm{~cm}$

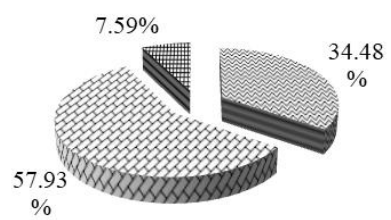

$>160 \mathrm{~cm}$

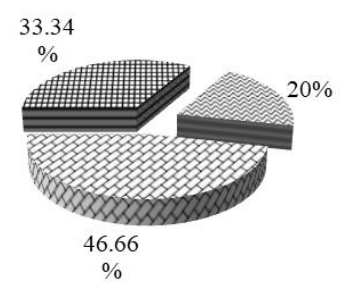

Empty - Trace

\& Quarter Full - Half Full

\# Three fourth Full - Gorged

Figure 1. Size (fork length) based feeding intensity of Thunnus albacares. 


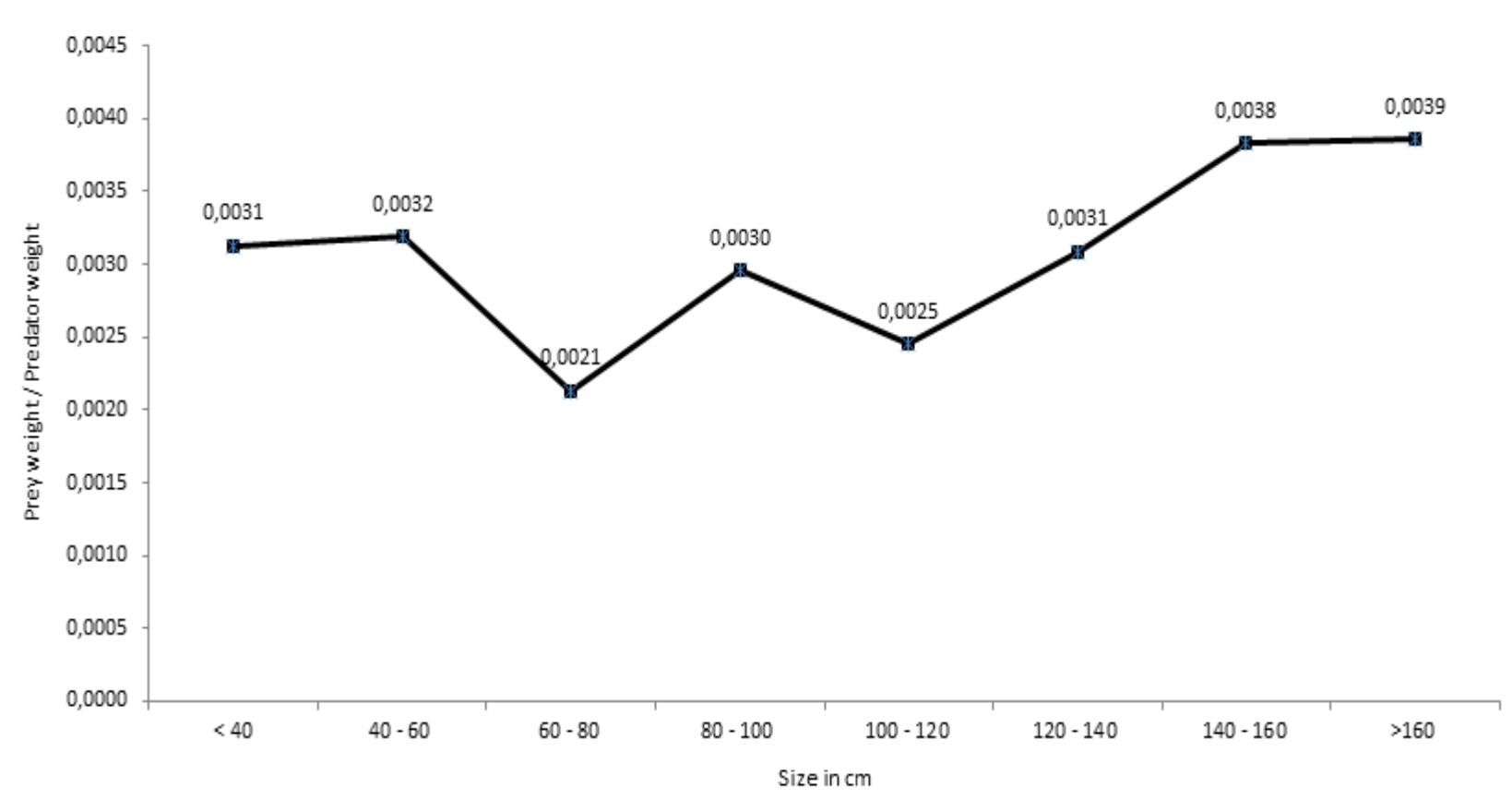

Figure 2. Prey to predator weight in different length classes of Thunnus albacares.

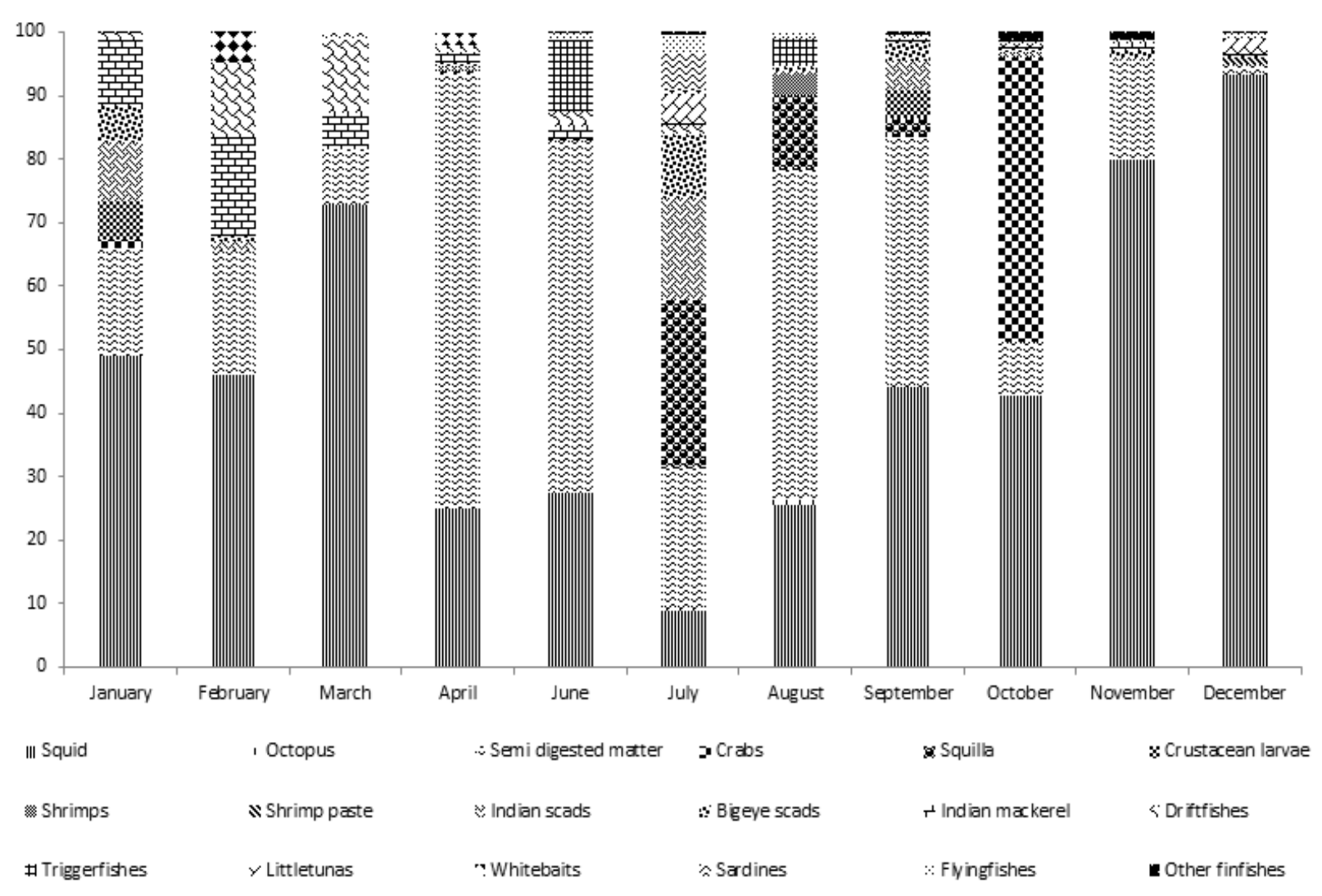

Figure 3. Index of relative importance (\%) of various prey items encountered in the stomach contents of Thunnus albacares landed during $2012-2015$. 


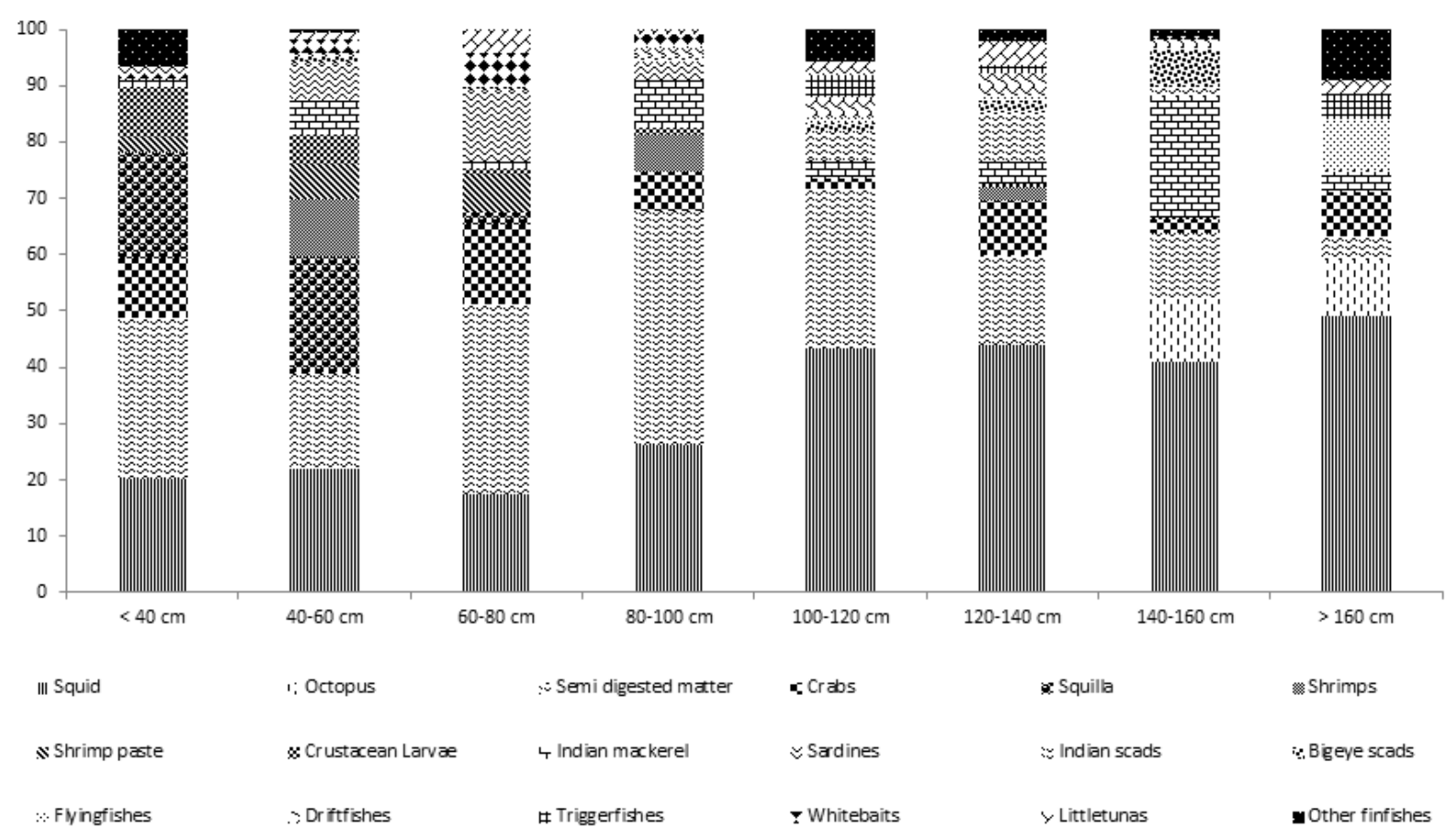

Figure 4. Size (fork length) based major prey items (IRI \%) of Thunnus albacares.

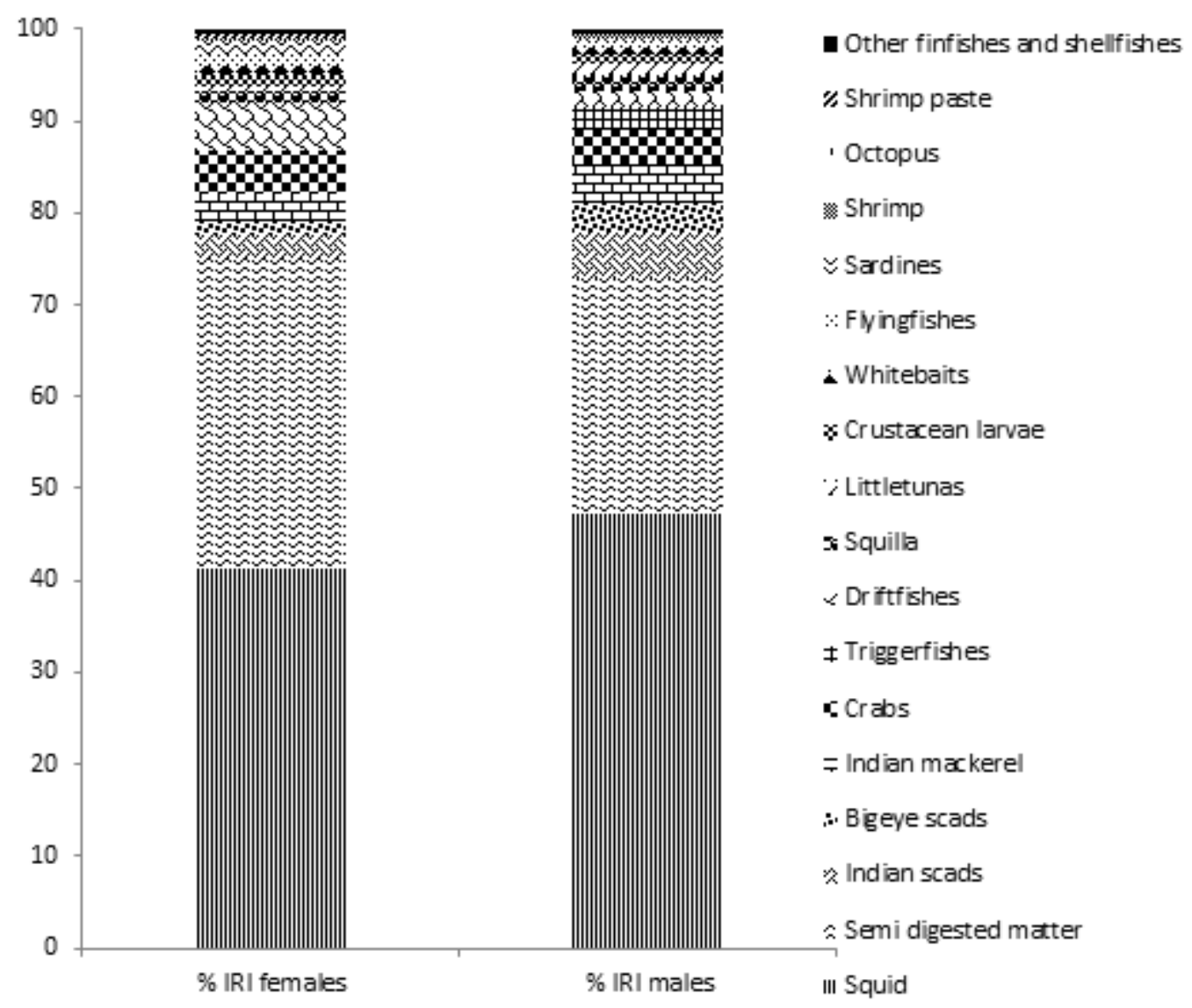

Figure 5. Index of Relative Importance (\%) of various prey items encountered in the stomach contents of males and females of Thunnus albacares. 
squilla, shrimps and paste shrimp) constituted $8.01 \%$ of the diet in females and $6.64 \%$ in males. Teleost fishes as prey items formed $20.34 \%$ in males and $16.74 \%$ in females, with the differences contributed mostly by the higher consumption of carangids in males.

\section{Similarity/Dissimilarity Studies of IRI\%}

Similarity Percentage of various prey items in stomachs of $T$. albacares was $71.36 \%$ for the years 2012 and 2015 (cluster 1), whereas during 2013 and 2014 (cluster 2), the similarity percentage of prey items was $71.21 \%$. The dissimilarity percentage of annual prey abundance between the two clusters was 37\% (Figure $6)$.

Based on Bray Curtis similarity model, month-wise cluster analysis of female (Figure 7) and male (Figure 8) prey abundance revealed the presence of three clusters. For females, cluster one was during February, March and June; cluster two was during November and December and cluster three was during January, April, August and September with similarity percentage values of $69.41 \%, 69.22 \%$ and $64.28 \%$ respectively. Maximum similarity percentage of female prey abundance was $86.48 \%$ during February and March. In males, cluster one was during January and September; cluster two was during February, March and November and cluster three was during April, June and August with similarity percentage values of $76.03 \%, 69.17 \%$ and $66.48 \%$ respectively.

\section{Prey-Specific Abundance and Niche Breadth}

Feeding strategy revealed $T$. albacares to be a more of specialized feeder, feeding within a specific niche width (Table 1). Orders Teuthida, represented by the squid and Perciformes, represented mostly by scombrids and carangids were the dominant prey as indicated in their high frequency of occurence. Prey belonging to the order Perciformes were eaten by nearly half the fishes and prey belonging to the order Teuthida were eaten by more than one-quarter of the fishes. Varying degrees of specialisation on different prey taxa was also observed with high specific abundance for orders Teuthida, Perciformes and Decapoda. Other orders showed low specific abundance and occurence and could have been consumed when they were found in association with the dominant prey items. Levins Standardized Niche Breadth Index and Levins Niche Breadth Index were 2.60 and 0.16 , respectively signifying relatively limited niche. Levins Standardized Niche Breadth Index was significantly higher during the monsoon (0.35) (July - October) months, than during the summer (0.14) (March - June) and winter (0.10) (November - February) months.

\section{Discussion}

Observations on the food composition as revealed from the stomach content analysis showed that squids, crabs and teleost fishes were the major component of food items, with squids dominating. T. albacares generally feed during daytime, feeding primarily on near-surface fishes, squids, and swimming crabs (Buck, 1997) with intense predatory activity during the dawn and sunset (Roger \& Grandperrin, 1976). In comparison with the earlier studies (Rohit et al., 2010; Alverson 1963; Potier et al., 2004; Dissanayake, et al., 2008; Abdussamad et al., 2012; Pradeep et al., 2014), who reported fish as their main dietary content, in the present study, squids were observed as the major prey items. However, Kaymaram, 2000; and Perera et al., 2015 also reported squid and crustaceans to be the major prey items. Alverson (1963) reported on a wide variety of food items and changes in species composition from area to area and concluded that $T$.

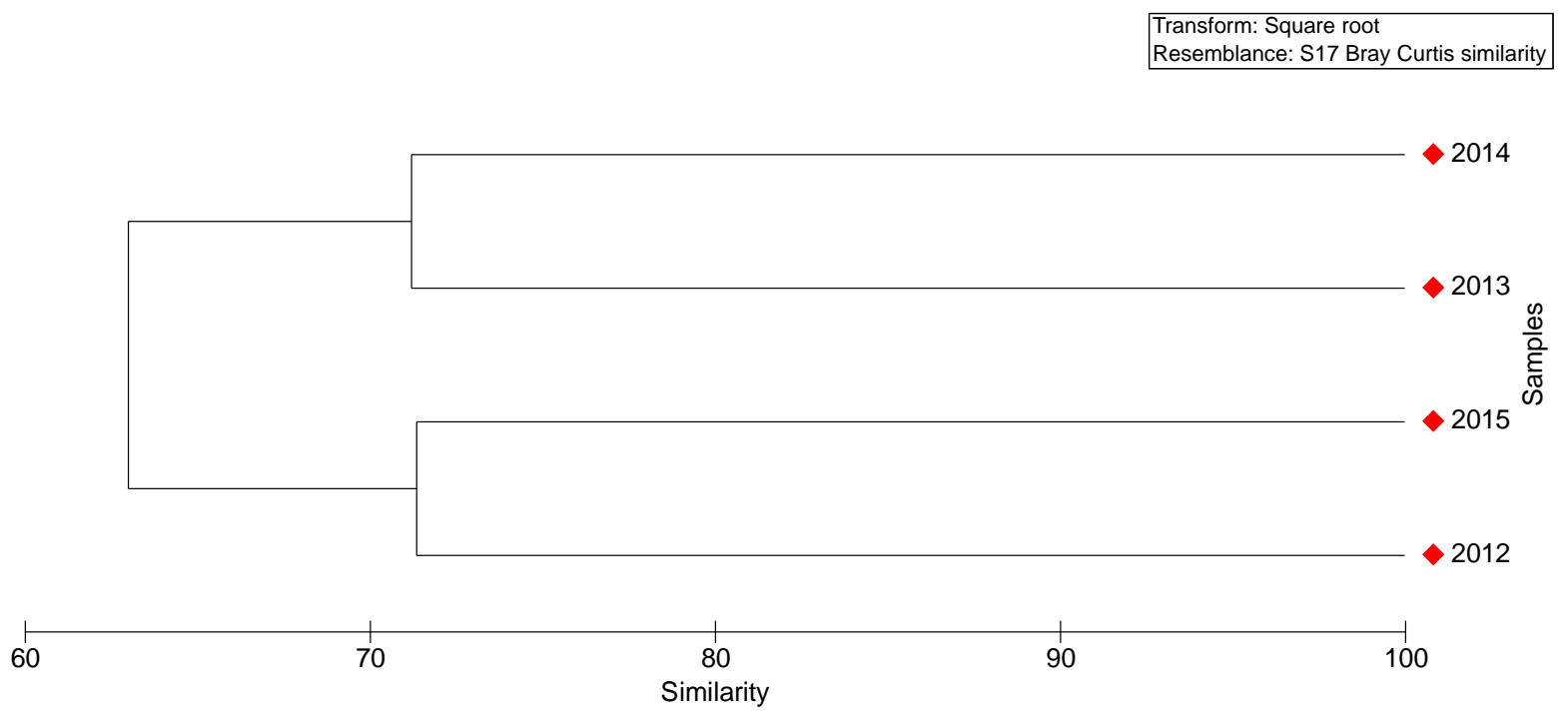

Figure 6. Annual prey abundance similarity of Thunnus albacares. 


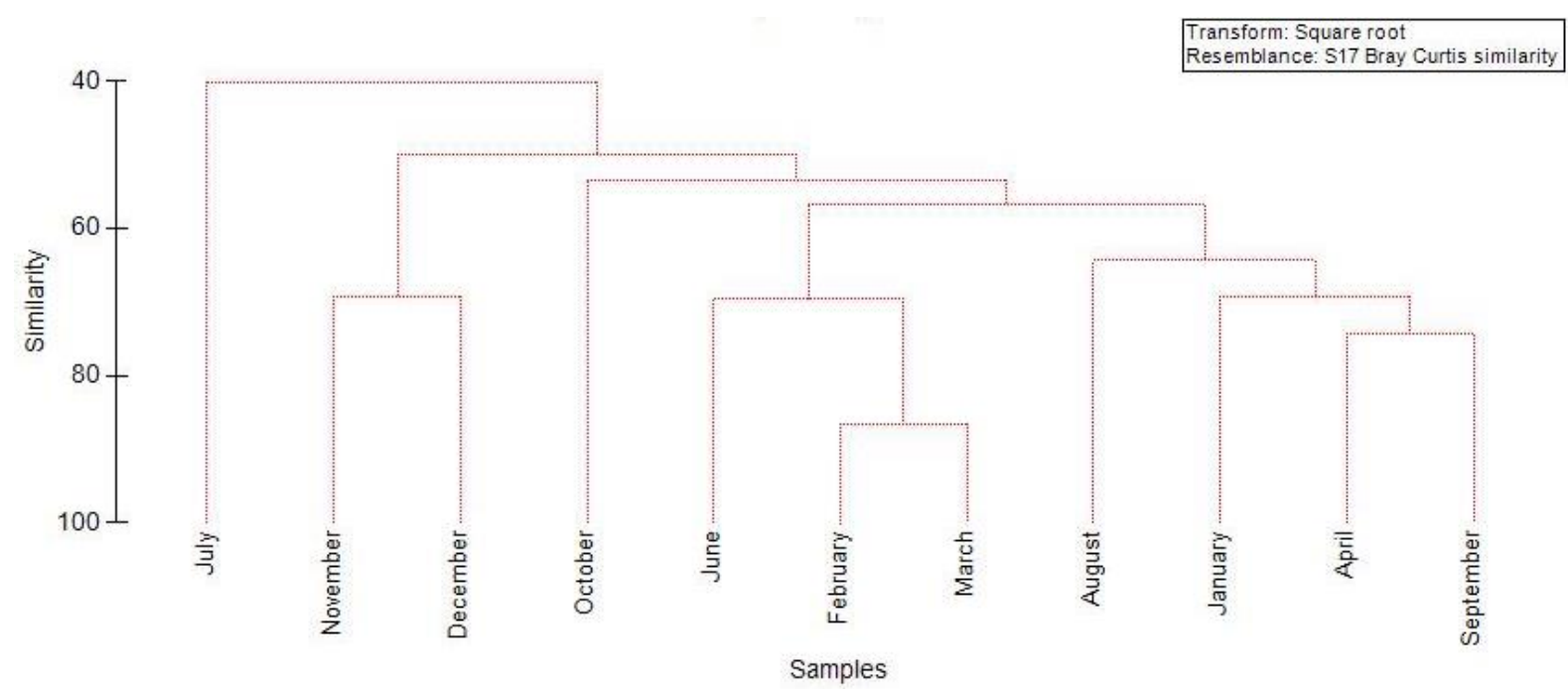

Figure 7. Seasonal prey abundance similarity in females of Thunnus albacares.

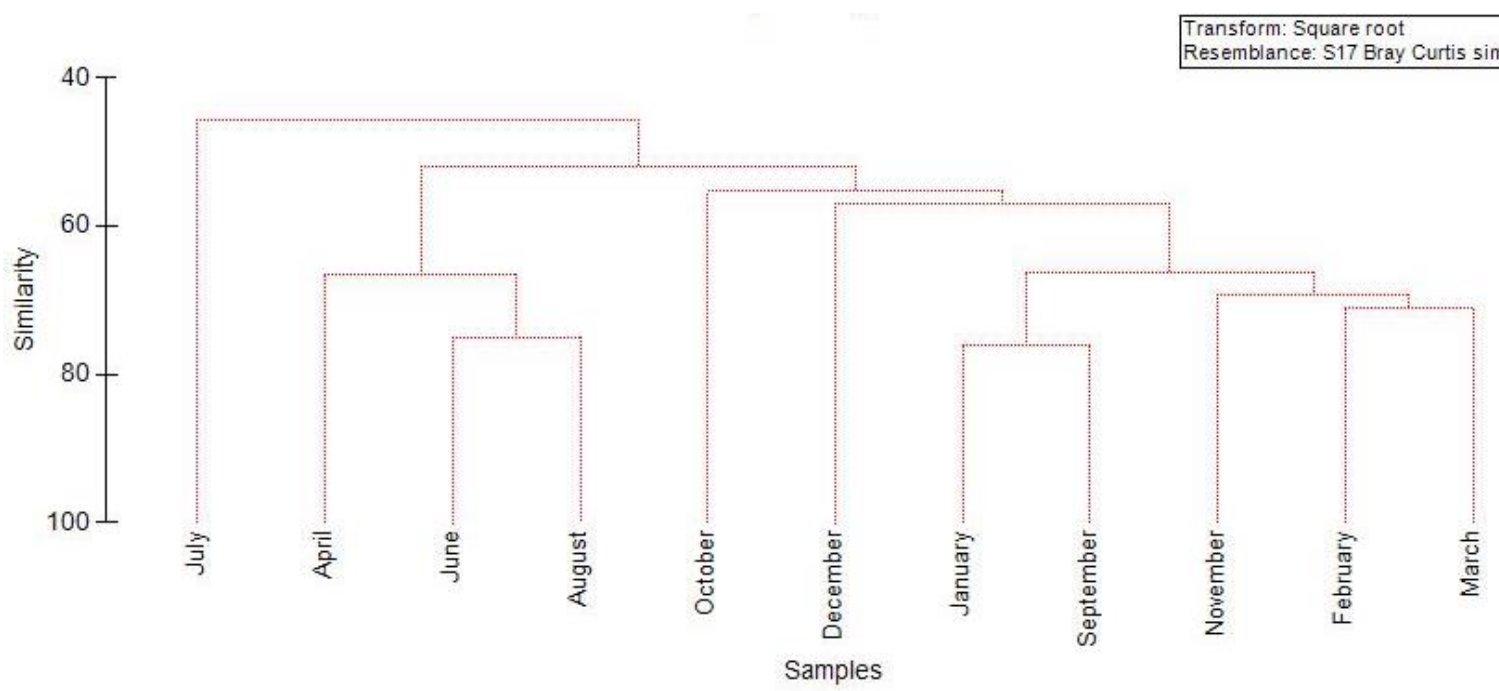

Figure 8. Seasonal prey abundance similarity in males of Thunnus albacares.

Table 1. Feeding strategy of Thunnus albacares

\begin{tabular}{lcc}
\hline Orders & Prey-specific Abundance \% & Frequency of Occurence \% \\
\hline Decapoda & 0.07 & 13.61 \\
Clupeiformes & 0.06 & 4.58 \\
Perciformes & 0.49 & 30.11 \\
Tetraodontiformes & 0.02 & 1.33 \\
Sepiidae & 0.00 & 0.11 \\
Teuthidae & 0.28 & 44.53 \\
Beloniformes & 0.02 & 0.69 \\
Stomatopoda & 0.03 & 4.75 \\
Octopoda & 0.01 & 0.24 \\
Sygnathiformes & 0.00 & 0.04 \\
Anguilliformes & 0.00 & 0.04 \\
\hline
\end{tabular}


albacares are non-selective feeders, foraging on whatever pelagic or benthic organisms that are locally available. Roger (1994) and Ménard \& Marchal (2003) also recorded such non-selective foraging and suggested that once the prey concentration of one target species is detected, tuna can feed on this concentration until satiation. Abundance of a single species (squids, carangids, mackerels and semi digested fishes) in the stomachs (full and three-fourth full condition) of wellfed $T$. albacares during the present study is indicative of such a feeding behaviour. The species diversity in the diet is higher than that reported in the earlier studies of Sudarshan and John (1994). This may be related to the fact that the samples collected for the present study covered both the coastal and oceanic regions.

A switch in the diet to teleost fishes at sizes more than $50 \mathrm{~cm}$ fork length was observed in unison to the findings of Maldeniya, 1996 and Weng et al., 2015, who reported fishes of above $50 \mathrm{~cm}$ fork length to become piscivorous with maximum consumption of cephalopods and crabs between $80-129 \mathrm{~cm}$ fork length. This could be attributed to the fact that with increase in mouth and body size of the fish, ontogenic shifts in diet contents permits it to catch a wide range of prey sizes and types (Labropoulou, \& Eleftheriou, 1997). Feeding preferences were found not to vary significantly between the sexes. Sex based feeding tendency indicated $T$. albacares to be a non-specific predator with feeding in sexes depending on the prey availability. The rare occurrence of myctophids, unicorn cod and absence of other fishes or crustaceans which constitutes the Deep Scattering Layer in the diet components in the samples analysed is agreeable with the observations of Roger and Grandperrin (1976) and Potier et al. (2004), who reported that the micronektonic fish preyed upon by $T$. albacares are mostly the epipelagic ones and not, the vertically migrating ones which constitutes the deep scattering layer. The occurrence of small prey such as brachyuran megalopa in the stomach may be related to their availability in the vicinity and food selectivity of the gill rakers as suggested by Magnuson and Heitz (1971). Also, higher IRI\% for semi digested finfishes and shellfishes indicate rapid digestive capability of the fish. Hence, stomach contents, in the present study, were analysed on the same day in which the fish was landed.

In the present study, with increase in size, feeding intensity increased. Fishes measuring $120 \mathrm{~cm}$ or more in fork length were found to possess mostly quarter full gorged stomachs. Also, prey weight in relation to predator weight was high in fishes over $140 \mathrm{~cm}$ fork length. With increase in age and size of the fish, several morphological alterations happen resulting in enhanced mouth gape/aperture along with improved locomotive ability of the fish, thereby increasing their efficiency in catching prey (Ghosh, 2014). Annual similarity in the diet contents reflected the annual abundance and availability of various prey groups. Seasonal clusters in female and male prey abundance also indicated a nonselective feeding nature and the similarities in food composition between months could be inferred as caused due to the availability of particular prey species in those months in the habitat.

Abundance of species belonging to the orders Teuthida, Perciformes and Decapoda is indicative of a specialized feeding pattern in T. albacares. Limited niche width with varying degrees of specialised feeding on different orders was observed in the present study. However, as the orders Perciformes and Decapoda represent a wide variety of species, therefore, it can be concluded that $T$. albacares is a non-selective feeder, with the abundance and occurence of prey influenced more by their availability. Again, higher niche breadth during monsoon could be due to higher diversity of prey items. Research conducted by Inter American Tropical Tuna Commission (IATTC) indicated that T. albacares are generalist feeders and do not seek out specific prey species (Rohit et al., 2010).

Apex predators like $T$. albacares play a very important role in the tropical open oceans. They are abundant and ubiquitous in the epipelagic ecosystem and produce substantial structural changes in the ecosystem when removed by fishing (Cox et al., 2002; Watters et al., 2003) and could have repercussions on the food web structure through top down, trophic cascades (Kitchell et al., 1999). The present study on the diet of $T$. albacares adds to the knowledge on its role in the food web and will aid in evolving improved exploitation strategies, especially for an ecosystembased management of $T$. albacares fisheries along the east coast of India.

\section{Acknowledgements}

Gratitude is expressed by the authors to Director, ICAR-CMFRI and Head, Pelagic Fisheries Division, ICARCMFRI for the encouragement and whole-hearted support provided for the study. The contribution of Indian Council of Agricultural Research for financing the study through the Institute funded research project entitled "Development of strategies to sustain the stock and fishery of large pelagics in Indian waters" project code IXX09380 deserves great appreciation.

\section{References}

Abdussamad, E.M., Koya, K.P., Rohit, P., Joshi, K.K., Ghosh, S., Elayathu, M.N.K., \& Rao, G.S. (2012). Fishery of yellowfin tuna Thunnus albacares (Bonnaterre, 1788) in the Indian EEZ with special reference to their biology and population characteristics. Indian Journal of Fisheries, 59(3), 43-51.

http://eprints.cmfri.org.in/9105/1/Abdussamad_4351.pdf

Alverson, F.G. (1963). The food of yellowfin and skipjack tunas in the eastern tropical Pacific Ocean. Inter-American Tropical Tuna Commission Bulletin, 7(5), 293-396.

Amundsen, P.A., Gabler, H.M., \& Staldvik, F.J. (1996). A new approach to graphical analysis of feeding strategy from stomach contents data-modification of the Costello 
(1990) method. Journal of fish biology, 48(4), 607-614. https://doi.org/10.1111/j.1095-8649.1996.tb01455.x

Buck, E.H. (1997). Dolphin Protection and Tuna Seining, CRS Issue Brief for Congress, No. 96011. Washington: Environment and Natural Resources Policy Division, U.S. Congressional Research Service.

Clarke, K.R., \& Gorley, R.N. (2006). Primer. Primer-E (6 $6^{\text {th }}$ edition).

Cox, S.P., Essington, T.E., Kitchell, J.F., Martell, S.J., Walters, C.J., Boggs, C., \& Kaplan, I. (2002). Reconstructing ecosystem dynamics in the central Pacific Ocean, 1952 1998. II. A preliminary assessment of the trophic impacts of fishing and effects on tuna dynamics. Canadian Journal of Fisheries and Aquatic Sciences, 59(11), 17361747. https://doi.org/10.1139/f02-138

Dissanayake, D.C.T., Samaraweera, E.K.V., \& Amarasiri, C. (2008). Fishery and feeding habits of yellowfin tuna (Thunnus albacares) targeted by coastal tuna longlining in the north western and north eastern coasts of Sri Lanka. Sri Lanka J Aquat Sci, 13, 1-21.

FAO, 2016. The state of world fisheries and aquaculture 2016. Contributing to food security and nutrition for all. Food and agriculture organization of the United Nations, Rome. http://www.fao.org/3/a-i5555e.pdf

Ghosh, S. (2014). Fishery, reproductive biology and diet characteristics of Bombay duck Harpadon nehereus from the Saurashtra coast. Indian Journal of Marine Sciences, 43(3), 418-426. http://nopr.niscair.res.in/handle/123456789/27333.

Govindraj, K., John, M.E., Premchand, B., Unnikrishnan, N., Jacob Thomas \& Somvanshi, V.S. (2000). Oceanic Tuna resources in the North West region of India EEZ. Bulletin of Fishery Survey of India (No. 27). Fishery Survey of India.

John, M.E. (1995). Studies on yellowfin tuna, Thunnus albacares (Bonnaterre, 1788) in the Indian Seas (PhD Thesis). University of Mumbai.

Kaymaram, F. (2000). Population dynamics and management of yellowfin tuna (Thunnus albacares) of the Oman Sea (PhD Thesis). Islamic Azad University, Science and Research Branch.

Kitchell, J.F., Boggs, C.H., He, X. \& Walters, C.J., (1999). Keystone predators in the Central Pacific. Ecosystem Approaches to Fisheries Management. In. Proceedings of the Symposium on Ecosystem Considerations in Fisheries Management (pp 665-684). University of Alaska Sea Grant, AK-SG-99-01. 756 pp.

Labropoulou, M., \& Eleftheriou, A. (1997). The foraging ecology of two pairs of congeneric demersal fish species: importance of morphological characteristics in prey selection. Journal of fish biology, 50(2), 324-340. https://doi.org/10.1111/j.1095-8649.1997.tb01361.x

Levins, R. (1968). Evolution in changing environments: some theoretical explorations (No. 2). Princeton University Press.

Magnuson, J.J., \& Heitz, J.G. (1971). Gill raker apparatus and food selectivity among mackerels, tunas and dolphins. Fish. Bull, 69(2), 361-370.

https://pdfs.semanticscholar.org/3885/a916040773ffdf 7d206532bd661b010cc6cf.pdf

Maldeniya, R. (1996). Food consumption of yellowfin tuna, Thunnus albacares, in Sri Lankan waters. Environmental biology of fishes, 47(1), 101-107. https://doi.org/10.1007/BF00002384
Ménard, F., \& Marchal, E. (2003). Foraging behaviour of tuna feeding on small schooling Vinciguerria nimbaria in the surface layer of the equatorial Atlantic Ocean. Aquatic Living Resources, 16(3), 231-238. https://doi.org/10.1016/S0990-7440(03)00040-8.

Perera, H.A.C.C., Maldeniya, R., Weerasekara, S.A., \& Senadheera, S.P.S.D. (2015). Opportunistic dietary nature of yellowfin tuna (Thunnus albacares): occurrence of polythene and plastic debris in the stomach. In. IOTC proceedings of Working Party on Tropical Tunas, WPTT17-19. IOTC.

Pillai, P.P., Said Koya, K.P., Pillai, N.G.K. \& Jayaprakash, A.A. (1993). Fishery biology of yellowfin tuna occurring in oceanic fishing in Indian Seas. In. John, M. E., \& Sudarshan, D. (Eds). Tuna research in India. Fishery Survey of India.

Pinkas, L., Oliphant, M.S. \& Iverson, I.L.K. (1971). Food habits of albacore, bluefin tuna and bonito in Californian waters. Fish Bulletin (No. 152). Dept of Fish and Game. $105 \mathrm{pp}$.

Potier, M., Marsac, F., Lucas, V., Sabatié, R., Hallier, J.P., \& Ménard, F. (2004). Feeding partitioning among tuna taken in surface and mid-water layers: the case of yellowfin (Thunnus albacares) and bigeye (T. obesus) in the western tropical Indian Ocean. Western Indian Ocean Journal of Marine Science, 3(1), 51-62.

Pradeep, H.D., Swapnil, S.S., Dwivedi, S.K., Ramachandran, S., \& Premchand. (2014). Distribution, abundance and biology of yellowfin tuna, Thunnus albacares (Bonnaterre, 1788) in the Andaman and Nicobar waters, Journal of the Andaman Science Association Vol. 19(2), $191-200$.

Roger, C. 1994. On feeding conditions for surface tunas (yellowfin, Thunnus albacares and skipjack, Katsuwonus pelamis) in the western Indian Ocean. In: Ardill, J. D. (Ed.), Proceedings of the expert consultation on Indian Ocean Tunas. 5th session. IPTP Coll. Vol. Work, Doc., 8: pp.131-135.

Roger, C., \& Grandperrin, R. (1976). Pelagic food webs in the tropical Pacific. Limnology and Oceanography, 21(5), 731-735. https://doi.org/10.4319/lo.1976.21.5.0731

Rohit, P., \& Ram Mohan, K. (2009). Fishery and biological aspects of yellowfin tuna Thunnus albacares along Andhra coast, India. Asian Fisheries Science, 22(1), 235244.

Rohit, P., Rao, G.S., \& Ram Mohan, K. (2010). Feeding strategies and diet composition of yellowfin tuna Thunnus albacares (Bonnaterre, 1788) caught along Andhra Pradesh, east coast of India. Indian Journal of Fisheries, 57(4), 13-19.

Rohit, P., Rao, G.S., \& Rammohan, K. (2008). Yellowfin tuna fishery by traditional fishermen at Visakhapatnam, Andhra Pradesh. Journal of the Marine Biological Association of India, 50(1), 62-68.

Somvanshi, V.S. (2002). Review of biological aspects of yellowfin tuna (Thunnus albacares) from the Indian Ocean. In. IOTC Proceedings of Working Party on Tropical Tunas WPTT02-29 no. 5 (pp. 420-426). Shanghai, China.

Sudarsan, D. \& John, M.E. (1994). Further studies on biological aspects of yellowfin tuna in the Indian EEZ. In: Ardill, J.D. (Ed.), Proceedings of the expert consultation on Indian Ocean tunas, 5th session IPTP collective vol., 8. pp. 135141. 
Vijaykumaran, K., Parasuraman, P.S., Rajkumar, S.A., \& Nagarajan, G. (1992). A study on the food and feeding habits of yellowfin tuna (Thunnus albacares) caught in Andaman waters on Indian EEZ by tuna longlining. Bulletin of Fishery Survey of India (No. 24). Fishery Survey of India.

Watters, G.M., Olson, R.J., Francis, R.C., Fiedler, P.C., Polovina, J.J., Reilly, S.B., Aydin, K.Y., Boggs, C.H., Essington, T.E., Walters, C.J., \& Kitchell, J.F. (2003). Physical forcing and the dynamics of the pelagic ecosystem in the eastern tropical Pacific: simulations with ENSO-scale and globalwarming climate drivers. Canadian Journal of Fisheries and Aquatic Sciences, 60(9), 1161-1175. https://doi.org/10.1139/f03-100

Weng, J.S., Lee, M.A., Liu, K.M., Hsu, M.S., Hung, M.K., \& Wu, L.J. (2015). Feeding ecology of juvenile yellowfin tuna from waters southwest of Taiwan inferred from stomach contents and stable isotope analysis. Marine and Coastal Fisheries, 7(1), 537-548.

https://doi.org/10.1080/19425120.2015.1094157 